\title{
Superbohaterki $w$ kinie przed powstaniem Marvel Cinematic Universe. Historia adaptacji kobiecych kostiumów superbohaterskich
}

\author{
KLAUDIA SRUL \\ Instytut Filmu, Mediów i Sztuk Audiowizualnych \\ Uniwersytet im. Adama Mickiewicza w Poznaniu
}

\begin{abstract}
Aвstract. Srul Klaudia, Superbohaterki w kinie przed powstaniem Marvel Cinematic Universe. Historia adaptacji kobiecych kostiumów superbohaterskich [Superheroines in movies before Marvel Cinematic Universe. A history of female superhero costume adaptations]. "Images" vol. XXIX, no. 38. Poznań 2021. Adam Mickiewicz University Press. Pp. 274-282. ISSN 1731-450X. DOI 10.14746/i.2021.38.18.

The article focuses on changes within superhero comic book movie adaptations from 1941 (Adventures of Captain Marvel premiere) to 2008 (the creation of Marvel Cinematic Universe) in the aspect of designing female characters' costumes. Author's refelections are based on the article From the Top of the Cowl to the Tip of the Cape. The Cinematic Superhero Costume as Impossible by Dru H. Jeffries published in 2013 in „Cinephile: The Univesity of British Columbia's Film Journal". The author of the cited paper focuses on the topic of adapting male comic book characters' costumes which is a starting point for the author of this article for in-depth analysis of this phenomenon including female superhero images.
\end{abstract}

KEYworDs: superhero films, comics, Marvel Comics, DC Comics, female characters, costume

Z kart komiksu na ekran - problem adaptacji kostiumów superbohaterskich

Dru H. Jeffries w pierwszych akapitach swojego artykułu From the Top of the Cowl to the Tip of the Cape. The Cinematic Superhero Costume as Impossible Garment $\mathrm{z} 2013$ roku zwraca uwage, jak ważnym narzędziem promocyjnym jest kostium filmowego superbohatera $\mathrm{i}$ jak, paradoksalnie, niewielu badaczy gatunku poświęca uwagę tej materii[1]. Autor nazywa kostium superbohaterski obiektem fascynacji, który ucieleśnia tożsamość bohatera, równocześnie stając się przedmiotem fetyszyzacji ze strony fanów[2]. Jeffries analizuje zmiany, jakie doko-

[1] D.H. Jeffries, From the top of the cowl to the tip of the cape. The cinematic superhero costume as impossible garment, „Cinephile: The University of British Columbia's Film Journal” 2013, vol. 9, nr 2, s. 31 .

[2] Ibidem.

[3] Ibidem. nały się w sposobie projektowania kostiumów na potrzeby filmów superhero na przestrzeni lat. Kluczowym elementem jego rozważań jest to, w jaki sposób filmowcy radzą sobie z przeniesieniem kostiumów z kart komiksów na ekran kinowy. Przed przyjrzeniem się samej ewolucji strojów warto jednak zwrócić uwagę na trudności, jakie niesie ze sobą w tej materii zmiana medium - z komiksowego na filmowe.

Autor przywołanego artykułu wymienia trzy kluczowe elementy komiksowych kostiumów, które muszą uwzględniać filmowcy: materiał, z którego wykonany jest strój, moment transformacji $z$ cywila w superbohatera oraz relacja między zachowaniem prawdopodobieństwa życiowego a stylizacją, charakterystyczną dla medium komiksu[3].

Analiza specyfiki medium komiksowego pozwala dojść do wniosku, że ograniczenia, jakie nakłada na filmowców adaptacja komiksu, pozwalają im niekiedy uniknąć błędnych decyzji. 
Jednym z tych ograniczeń jest wyłącznie wyobrażony ruch[4]. Z tego właśnie powodu rysownicy mogą sobie pozwolić na komponowanie kadrów, w których superbohaterowie przyjmują niemożliwe anatomicznie pozy, a żaden, nawet najmniej pragmatyczny kostium, nie krępuje ich ruchów, nie spada i wytrzymuje najcięższe warunki. Filmowy kostium nie tylko musi dobrze się prezentować na aktorze, ale i nadawać się do noszenia. Dodatkowo musi spełniać określone funkcje w scenach akcji.

Innym ograniczeniem przy adaptacji komiksu jest konieczność częstego stosowania elips. Również ono staje się w wielu przypadkach udogodnieniem. Jeffries zauważa, że elipsy służą w komiksach superbohaterskich między innymi jako narzędzie do ukazania transformacji w superbohatera, a raczej jej nieukazywania. Widoczny na jednym obrazku Clark Kent na następnym jest już Supermanem. Przemiana, która dokonała się między kadrami, nie budzi niczyjego zaskoczenia. Dzieje się tak dzięki elementowi struktury komiksu, który Scott McCloud nazywa odstępem (ang. gutter) [5]. Wkład czytelnika w komiks polega, zdaniem twórcy i badacza, przede wszystkim na dopowiedzeniu sobie, co dzieje się między poszczególnymi kadrami. Owo dopowiedzenie, nazwane przez McClouda dookreśleniem (ang. closure) [6], pozwala na zachowanie ciągłości narracyjnej - pojedyncze kadry komiksowe stają się w głowie czytelnika spójną historią. Tego elementu nie da się wiernie zaadoptować do filmu. Filmowcy radzą sobie z tym problemem, pomijając moment transformacji (metoda, która, podobnie jak ta komiksowa, wymaga pracy intelektualnej odbiorcy), albo decydując się na pokazanie przemiany na ekranie. Druga z tych możliwości współcześnie wybierana jest niezwykle rzadko i niemal wyłącznie w scenach, w których wykorzystywane jest CGI (computer-generated imagery)[7]. W pionierskich produkcjach superbohaterskich znacznie częściej decydowano się na ukazanie przemiany bohatera. Wówczas mógł to być element atrakcyjny dla widza, pozwalający na pełną immersję w filmową opowieść. Dziś sceny przemiany Wonder Woman (obracająca się w kółko Lyn- da Carter) czy Supermana z lat siedemdziesiątych (Christopher Reeve przywdziewający strój $\mathrm{w}$ obracających się z ponadprzeciętną prędkością drzwiach obrotowych) postrzegane są raczej w kategoriach uroczego kampu.

Ostatnią wskazaną przez Jeffriesa trudnością, przed którą stają filmowcy przy adaptacji materiału komiksowego, jest „jedność” kostiumu[8]. Większość superbohaterskich strojów łączy pewną ciekawą sprzeczność: $\mathrm{z}$ jednej strony na kartach komiksów odnaleźć można kadry, w których bohater zdejmuje pojedynczy element kostiumu, z drugiej zaś rysownicy każą wierzyć odbiorcom, że dany kostium jest tak naprawdę jednoczęściowy. Jeffries powołuje się między innymi na przypadek maski Spider-Mana[9]. W komiksach jest ona wielokrotnie ściągana przez bohatera, jednak w momencie ponownego założenia „magicznie” łączy się z resztą stroju (co rzeczywiście można zauważyć, na przykład, gdy przyjrzymy się zachowaniu kostiumu podczas walki).

Filmowcy stają tu przed kolejnym dylematem dotyczącym „prawdopodobieństwa” kostiumów. Ponownie wyszczególnić można dwa podejścia[10]. U podstaw pierwszego $\mathrm{z}$ nich leży zawieszenie niewiary, które pozwala na dosłowne przeniesienie tego zabiegu na ekran kinowy, jak chociażby w przypadku serii filmów Sama Raimiego o Spider-Manie (2002-2007). Reżyser nie zachowuje w nich spójności: strój, podobnie jak w komiksach, jest wieloczęściowy, gdy bohater musi zdjąć maskę, jednak staje się jednoczęściowy w scenach przemieszczania się lub walki. Drugi rodzaj podejścia wybrał Tim Burton, adaptując historię Batmana. Jeffries

[4] Ibidem, s. 31.

[5] S. McCloud, Zrozumieć komiks, Warszawa 2015, s. 66.

[6] Ibidem, s. 63.

[7] W scenach takich jak założenie mechanicznej zbroi przez Iron Mana czy przemiana Bruce’a Bannera w generowanego komputerowo Hulka.

[8] D.H. Jeffries, op.cit., s. 32.

[9] Ibidem, s. 32.

[10] Ibidem, s. 34-35. 
przywołuje w tym miejscu scenę z filmu Powrót Batmana, w której Michael Keaton dosłownie musi rozerwać gumowy kostium, by w finałowych scenach Batman mógł ujawnić przed Catwoman prawdziwą tożsamość.

Konkluzją przywołanego artykułu jest stwierdzenie, iż kwestia adaptacji komiksowego kostiumu, mimo rozwoju technologii, nadal przysparza filmowcom nie lada dylematów. Dzieje się tak z powodu konieczności przeniesienia rozwiązań wypracowanych przez jedno medium na grunt innego. Autor kończy swój wywód ironicznym zdaniem: „Te filmy być może dają radę przekonać widownię, że człowiek umie latać, ale nie udaje im się przekonać nas do czegoś, co wydaje się o wiele prostsze: że ten człowiek potrafi sam się ubrać”[11].

\section{Fazy rozwoju kostiumów filmowych superbohaterek}

Mając świadomość przywołanych trudności, z jakimi do dziś borykają się projektanci kostiumów filmowych superbohaterów, łatwiej zrozumieć przemiany, które dokonywały się przez lata w obrębie gatunku. Jeffries w swoim artykule wyszczególnia pewne (dość umowne) fazy rozwoju kostiumów superbohaterskich w kinie. Nie czyni jednak rozróżnienia ze względu na płeć bohatera, a przykłady dotyczą niemal wyłącznie bohaterów męskich. Dlatego właśnie periodyzacja zaproponowana przez autora stanowi dobry punkt wyjścia dla rozważań na temat kostiumów bohaterek kobiecych - tego, jakim przemianom ulegały damskie stroje na przestrzeni lat oraz czy owe przemiany różnią się znacząco od tych, które przeszły kostiumy męskie.

Pierwsza faza, zaproponowana przez Jeffriesa, sięga początków obecności komiksowych superbohaterów na dużym ekranie, czyli roku 1941 (premiera odcinkowego filmu Adventures

[11] Ibidem, s. 37 .

[12] Ibidem, s. 32.

[13] L. Daniels, Batman: The Complete History:

The life and times of the Dark Knight, San Francisco 2004, s. 113 i 115.

[14] Pierwszy komiks z Batgirl (DC Comics) pojawił się na sklepowych półkach pod koniec of Captain Marvel). Uniformy pierwszych filmowych inkarnacji postaci takich jak Superman, Batman czy Kapitan Ameryka przypominały wówczas bardziej kostiumy halloweenowe niż profesjonalne stroje przeznaczone do walki[12]. Przyczyną był oczywiście niski budżet oraz ograniczone możliwości technologiczne. Stąd też filmowcy starali się zaadaptować przede wszystkim pojedyncze charakterystyczne elementy poszczególnych komiksowych strojów. W przypadku niektórych $\mathrm{z}$ tych produkcji dodatkowym ograniczeniem był fakt, iż powstawały one w czerni i bieli. Niemożliwe było zatem zaprezentowanie widzom Supermana czy Kapitana Ameryki w rozpoznawalnych przez każdego odbiorcę barwach amerykańskiej flagi. Warto zauważyć, że w tej sytuacji wyjątkowo ważnym narzędziem promocyjnym okazywały się kolorowe plakaty reklamujące film.

Faza halloweenowych kostiumów ominęła kobiece bohaterki komiksów, gdyż filmowcy decydowali się początkowo wyłącznie na adaptacje przygód męskich herosów. Pierwszą superbohaterką, która zagościła na ekranie, była Batgirl. Nie był to jednak ekran kinowy, a telewizyjny, gdyż debiut Barbary Gordon przypadł na czasy świetności telewizji. Choć pierwsza postać nosząca miano Bat-Girl, Betty Kane, pojawiła się w zeszytach DC Comics w roku 1961, to właśnie córka komisarza Gordona do dziś pozostaje najbardziej rozpoznawalną Batgirl.

Postać Barbary Gordon została stworzona na potrzeby promocji popularnego $\mathrm{w}$ latach sześćdziesiątych serialu Batman (1966-1968). Twórcy, chcąc przyciągnąć żeńską widownię przed ekrany telewizorów, zwrócili się do Juliusa Schwartza z prośbą o powołanie do życia na kartach komiksu żeńskiej protagonistki, która będzie mogła dołączyć do drużyny serialowego Batmana w trzecim sezonie[13]. Kostium komiksowej Batgirl był zatem tworzony z myślą o udziale tej postaci w serialu. Podczas procesu adaptacji zmianie uległa jedynie kolorystyka - fioletowy kombinezon lepiej wpisywał się w kolorowy, serialowy świat niż komiksowa czerń[14]. Warto również zaznaczyć, iż strój Batgirl stanowi dopasowaną do kobiecej sylwet- 
ki wersję kostiumu Batmana, w związku z czym Barbara ostatecznie jest mniej roznegliżowana niż odsłaniający ramiona oraz nogi Robin.

Dla Jeffriesa to właśnie premiera serialu o Batmanie (1966) stanowi cezurę w periodyzacji dziejów filmowych kostiumów superbohaterskich. Zdaniem autora zarówno kostium Adama Westa, jak i ten noszony kilkanaście lat później przez Christophera Reeve’a (Superman, 1978) są przykładami nowego podejścia w dziedzinie superkostiumów, które mają być wykonane $\mathrm{z}$ cieńszych materiałów i bardziej przylegać do skóry[15]. O ile jednak na przykładzie stroju Supermana rzeczywiście zauważalny jest wspomniany progres, o tyle kostium Batmana wydaje się sytuować na pograniczu obu faz. Przede wszystkim porównanie kostiumu Adama Westa[16] i Lewisa Wilsona (wcześniejszy odtwórca roli Mrocznego Rycerza)[17] prowadzi do wniosku, iż strój Batmana nie zmienił się w ciągu dwudziestu lat (!) na tyle znacząco, by sytuować go w innej grupie. Jest to zrozumiałe, jeśli przyjąć fakt, iż serialowe przygody Batmana posiadały telewizyjny budżet oraz nadal były dość wczesnym przedstawicielem swego gatunku. Twórcy serialu, podobnie jak poprzednicy, adaptowali zatem przede wszystkim charakterystyczne elementy komiksowych kostiumów. Dodatkowym atutem serialowych strojów był natomiast kolor, wprowadzający kampową atmosferę.

Obok Batgirl w serialu pojawiła się jeszcze jedna prominentna postać kobieca. Catwoman to bohaterka zaliczana do bogatej galerii przeciwników Batmana, uwikłana w niejednoznaczną relację z Mrocznym Rycerzem. Mimo dwukrotnej zmiany aktorki odgrywającej tę rolę w ramach serii kostium Seliny Kyle przeszedł niewielkie zmiany. Twórcy zdecydowali się na przylegający do ciała czarny kombinezon ze złotymi elementami oraz charakterystyczne kocie uszy, nawiązujące do pseudonimu bohaterki[18].

Co ciekawe, kostium Catwoman, podobnie jak strój Batgirl, stanowi przykład oddziaływania medium filmowego na komiks. Do czasu premiery serialu kostium bohaterki na kartach komiksu składał się z peleryny oraz wydekoltowanej, dziwacznie skrojonej szaty odsłaniającej nogi [19]. We współczesnych wersjach stroju Catwoman widoczna jest inspiracja serialowym wizerunkiem, który przez lata zdążył wyewoluować - zarówno na łamach komiksów, jak i na dużym ekranie[20].

Widać zatem na omówionych przykładach, że serial o Batmanie $\mathrm{z}$ lat sześćdziesiątych nie daje się jednoznacznie zakwalifikować do żadnej z dwóch faz rozwoju kostiumów, zaproponowanych w artykule Jeffriesa. Nadal jest to bardziej niskobudżetowe halloweenowe przebranie (choć, dzięki możliwościom technicznym, wreszcie kolorowe) niż strój, który stara się spełnić komiksowy postulat przylegania do ciała i eksponowania umięśnionej sylwetki. Jeffries podkreśla w swoim tekście, iż realizacja tego postulatu na ekranie nie jest w pełni możliwa. Wynika to $\mathrm{z}$ faktu, iż dla komiksowego superbohatera kostium jest „drugą skórą”. Jak zauważa Scott Bukatman, stroje komiksowych herosów łączą rokokową fascynację ornamentyką (bogata kolorystyka, naramienniki, emblematy) z klasycystyczną ideą herosa odzianego

$1966 \mathrm{roku} ;<$ https://tiny.pl/rzmns>, dostęp: 24.05.2021. Yvonne Craig u boku Adama Westa i Burta Warda w serialu Batman, kilka miesięcy po komiksowym debiucie Batgirl (1966-1968): <https://tiny.pl/rzmnb>, dostęp: 24.05.2021.

[15] D.H. Jeffries, op.cit., s.32.

[16] Adam West w serialu Batman (1966-1968): <https://tiny.pl/rzmkg>, dostęp: 24.05.2021. [17] Lewis Wilson w roli Batmana w serialu kinowym z 1943 roku: <https://tiny.pl/rzmkq>, dostęp: 24.05.2021.

[18] Julie Newmar odgrywająca rolę Catwoman w dwóch pierwszych sezonach serialu: <https:// tiny.pl/rzmkc>, dostęp: 24.05.2021. Lee Meriwether w filmie kinowym $\mathrm{z}$ roku 1966: $<$ https:// tiny.pl/9mjgn>, dostęp: 24.05.2021. Eartha Kitt - sezon trzeci: <https://tiny.pl/rzmkk>, dostęp: 24.05.2021.

[19] Komiksowa Catwoman w kostiumie z lat czterdziestych: <https://tiny.pl/rzmkv>, dostęp: 24.05.2021.

[20] Okładka Catwoman \#11 z 2019 roku: <https://tiny.pl/rzmkz>, dostęp: 24.05.2021. 
w „idealną nagość" (ang. perfect nudity)[21]. Wraz z pojawieniem się w kinie koloru pierwszy z tych postulatów stał się możliwy do spełnienia, natomiast drugi nadal pozostaje nieosiągalny. $\mathrm{W}$ realnym świecie nie sposób w pełni oddać komiksowej estetyki kostiumu będącego równocześnie zbroją i sugestią wspomnianej nagości, dlatego właśnie filmowcy z czasem zaczęli rezygnować z prób jak najwierniejszego adaptowania komiksowych strojów, decydując się na poszukiwanie własnej artystycznej drogi.

Ciekawy przykład tych poszukiwań stanowi, mniej dziś pamiętany kostium Wonder Woman, który nosiła pierwsza odtwórczyni tej roli, Cathy Lee Crosby, w 1974 roku. Poza kolorystyką niczym nie przypomina on skąpego stroju komiksowej Amazonki i wydaje się jedynie codziennym ubraniem inspirowanym kostiumem Diany[22]. Film z udziałem Crosby wyemitowano jako pilot planowanego serialu telewizyjnego, który ostatecznie został anulowany. W jego miejsce, rok później, na ekranach telewizorów zagościł serial o tej samej bohaterce, z Lyndą Carter w roli głównej. Tym razem twór-

[21] D.H. Jeffries, op.cit., s. 32.

[22] Cathy Lee Crosby w roli Wonder Woman w pilocie anulowanego serialu: <https://tiny.pl/ rzm2X>, dostęp: 24.05.2021.

[23] Lynda Carter - do niedawna najbardziej znana aktorka wcielająca się w postać Diany: $<$ https://tiny.pl/rzm2g >, dostęp: 24.05.2021. Komiksowy strój Wonder Woman jest inspirowany utrwalonym $\mathrm{w}$ kulturze wizerunkiem antycznych herosów: <https://tiny.pl/rzm2t $>$, dostęp: 24.05.2021.

[24] Christopher Reeve, kultowy odtwórca roli Supermana, w stroju silnie inspirowanym komiksami: <https://tiny.pl/rzm29>, dostęp: 21.04.2020. [25] <https://www.boxofficemojo.com/release/ rl4050814465/weekend/>, dostęp: 24.05.2021. [26] Helen Slater jako Supergirl, kuzynka Kal-Ela, w żeńskiej wersji tego samego stroju. Uwagę zwraca spódniczka oraz odsłonięte nogi: <https:// tiny.pl/rzm2c>, dostęp: 24.05.2021.

[27] D.H. Jeffries, op.cit., s. 32.

[28] Alicia Silverstone, George Clooney i Chris O’Donnell jako członkowie Batrodziny w strojach przypominających zbroje: <https://tiny.pl/ rzm2f>, dostęp: 24.05.2021. cy nie zaryzykowali zmiany ikonicznego kostiumu, który okazał się niezwykle łatwy do wiernej adaptacji[23]. Carter od komiksowej Diany odróżnia natomiast sylwetka - wówczas angaż do roli superherosa nie wiązał się z koniecznością rozpoczęcia intensywnego treningu fizycznego.

Niedługo po debiucie cieszącego się sporą oglądalnością serialu Wonder Woman ekrany kinowe szturmem zdobył Superman. Twarzą serii filmów, początkowo reżyserowanych przez Richarda Donnera, był Christopher Reeve, którego kostium wyróżnia się na tle poprzedników - jest dopasowany do ciała aktora do tego stopnia, że udaje mu się nawet zarysować mięśnie[24]. Film zyskał sporą grupę fanów i okazał się komercyjnym sukcesem[25]. Nie dziwi zatem fakt, że twórcy filmowej Supergirl (1984) wykorzystali sprawdzony kostium jako źródło inspiracji dla stworzenia stroju postaci granej przez Helen Slater. Jest on przy tym wierny komiksowemu pierwowzorowi - ten również stanowi bowiem kobiecą wersję stroju Supermana[26].

Po wyjątkowo krótkiej „erze” przylegających do ciała kostiumów w kinie superbohaterskim pojawił się pomysł zrezygnowania $\mathrm{z}$ lateksowych strojów na rzecz grubszych kostiumów, pełniących funkcję zbroi. Stało się tak za sprawą filmów o Batmanie Tima Burtona (1989 i 1992 r.) oraz kontynuacji w reżyserii Joela Schumachera z 1995 i 1997 roku[27]. To właśnie w filmach drugiego $\mathrm{z}$ wymienionych reżyserów postulat eksponowania ciała został pociągnięty do ekstremum: w scenach przywdziewania superbohaterskich strojów zastosowane są zbliżenia na poszczególne elementy kostiumu, w tym nawet na wymodelowane $\mathrm{w}$ nim sutki.

Podczas gdy członkowie Batrodziny, w tym nowa inkarnacja Batgirl, przyodziani są w wytrzymałe kostiumy utrzymane w ciemnej kolorystyce[28], w przypadku złoczyńców zdecydowano się na pozostanie przy barwnych i w większości materiałowych kostiumach.

Jedyną superbohaterką występującą w przywołanej serii filmów jest Batgirl. Pojawiają się w nich jednak również dwie znane z komiksów, obdarzone supermocami antagonistki: Catwo- 
man (w tej roli Michelle Pfeiffer) oraz Poison Ivy (Uma Thurman).

Twórcy filmu Powrót Batmana (1992) zdecydowali się na przyodzianie bohaterki granej przez Pfeiffer w lateksowy, mocno przylegający do ciała strój. Przywodzi on na myśl kostiumy wykorzystywane do praktyk sadomasochistycznych[29]. Wybór ubioru koresponduje z gwałtowną zmianą charakteru Seliny Kyle po przemianie w Catwoman - z "cichej myszki”, pracującej jako sekretarka, w wyuzdaną nocną mścicielkę. Jest również dostosowany do mrocznego klimatu miasta Gotham, wykreowanego na ekranie przez Tima Burtona. Choć zagranie roli Catwoman było spełnieniem marzeń aktorki, swój kostium określa jako najbardziej niewygodny w całej karierze. Ekipa filmowa każdego dnia musiała najpierw pokryć Pfeiffer pudrem od stóp do głów, następnie wcisnąć ją w ciasny kostium i zastosować metodę pakowania próżniowego. Maska natomiast była na tyle ciasna, że aktorka wręcz się w niej dusiła[30].

Choć kolejny film o Mrocznym Rycerzu Batman i Robin (1998) - z założenia kierowany był do młodszej widowni niż filmy Tima Burtona, twórcy zdecydowali się na dość wierne zaadaptowanie skąpego komiksowego kostiumu Poison Ivy[31]. Grana przez Umę Thurman bohaterka odziana jest $\mathrm{w}$ body wykonane z materiału imitującego liście, zaś jej nogi i ramiona zakrywa zielony nylonowy materiał[32]. Podobnie jak w przypadku postaci Catwoman kostium odzwierciedla przemianę z przeciętnej kobiety (w tym przypadku ekolożki) w femme fatale panującą nad roślinami i męskim pożądaniem.

Wspomnienie o postaciach żeńskich antagonistek w kontekście analizy oscylującej wokół tematu żeńskich protagonistek może wydawać się zbędne. Ma ono jednak na celu zwrócenie uwagi na to, iż w filmach bazujących na komiksach DC Comics co jakiś czas znajdowało się miejsce dla postaci kobiecych obdarzonych supermocami. Dziś trudno uwierzyć, iż pierwszą superbohaterką konkurencyjnego wydawnictwa Marvel Comics na dużym ekranie była dopiero Rogue[33]. Wraz z nią w filmie pojawiły się dwie inne, znane z komiksów, członkinie grupy mutantów - Jean Grey oraz Storm, a także antagonistka Mystique. Długoletnia nieobecność superbohaterek Marvela w kinie może wynikać z faktu, iż filmy o Hulku czy Kapitanie Ameryce nie cieszyły się taką popularnością jak kolejne historie o Batmanie i Supermanie czy serial o Wonder Woman. Adaptatorzy komiksów DC Comics, mając na uwadze docelową grupę odbiorców, starali się w pierwszej kolejności wypromować postacie męskie. Sukces produkcji o Batmanie oraz Supermanie pozwolił na zaprezentowanie widowni, postaci takich jak Batgirl i Supergirl.

W tym samym czasie produkcje oparte na komiksach wydawnictwa Marvel Comics nie przynosiły porównywalnych wyników finansowych. W 1994 roku miała mieć miejsce premiera filmu o Fantastycznej Czwórce - pierwszej superbohaterskiej drużynie wykreowanej na kartach komiksów Marvela. Film nie doczekał się jednak nigdy oficjalnego wydania, choć zachowały się jego kopie. Produkcja ta jest warta wspomnienia, gdyż miała się w niej pojawić postać Sue Storm, która byłaby pierwszą superbohaterką Marvela przeniesioną na duży ekran.

Kostiumy filmowej Fantastycznej Czwórki stanowią dość wierne odwzorowanie komik-

[29] Michelle Pfeiffer w lateksowym kostiumie Catwoman w filmie Powrót Batmana (1992).

Uwagę przyciąga kusicielska poza bohaterki, a w tle widoczny jest bicz - nieodzowny rekwizyt Seliny Kyle: <https://tiny.pl/rzm22>, dostęp: 24.05.2021.

[30] B. Burton, 'Batman Returns' at 25: Stars reveal script cuts, freezing sets and aggressive penguins, 2017, <https://www.hollywoodreporter.com/heat-vision/batman-returns-at-25-stars-reveal-script-cuts-freezing-sets-aggressive-penguins-1013942> [dostęp: 21.04.2020.

[31] Komiksowy wizerunek Pameli Isley: <https://tiny.pl/rzm2z>, dostęp: 24.05.2021. [32] Uma Thurman w roli Poison Ivy w filmie Batman i Robin (1998): <https://tiny.pl/rzm8x>, dostęp: 24.05.2021.

[33] Wskazuję ją jako pierwszą z przywołanej trójki kobiet, gdyż pojawia się w jednej z początkowych scen filmu. 
sowych niebieskich strojów, osłaniających całe ciała bohaterów [34]. Wpisują się one w zaproponowaną przez Jeffriesa periodyzację, stanowiąc jednak relikt przeszłości (faza przylegających do ciała kostiumów wykonanych $\mathrm{z}$ cienkich materiałów). Paradoksalnie to właśnie w latach dziewięćdziesiątych wizerunek komiksowej Sue uległ drastycznej przemianie - bohaterka zaczęła nosić kostium odsłaniający nogi, brzuch i ramiona, a na jej piersiach pojawiło się cha-

[34] Rebecca Staab w roli Sue Storm w filmie Fantastyczna Czwórka (1994), który nie doczekał się nigdy oficjalnej premiery: <https://tiny.pl/ rzm8t>, dostęp: 24.05.2021. Fantastyczna Czwórka w klasycznych komiksowych kostiumach: <https://tiny.pl/rzmv2>, dostęp: 24.05.2021. [35] Kostium noszony w komiksach przez Sue w latach 1992-1994: <https://tiny.pl/rzm4f>, dostęp: 24.05.2021.

[36] Komiksowa Rogue kojarzona jest z żółto-zielonym kostiumem, brązową kurtką oraz burzą kasztanowych włosów z siwymi pasemkami; <https://tiny.pl/rzmvs>, dostęp: 24.05.2021. Anna Paquin w roli Rogue. Bohaterkę można rozpoznać wyłącznie po charakterystycznym siwym paśmie włosów: <https://tiny.pl/rzmv6>, dostęp: 24.05.2021. Komiksowa Jean Grey ma kilka rozpoznawalnych kostiumów, z których każdy utrzymany jest w jaskrawych barwach: $<$ https://tiny.pl/rzmvb>, dostęp: 24.05.2021. Kostium Storm, choć czarny, jest kolejnym przykładem wyrazistego komiksowego stroju superbohaterskiego. Nogi, ramiona oraz brzuch pozostają odsłonięte: <https://tiny.pl/rzmbq>, dostęp: 24.05.2021. Famke Janssen jako Jean Grey i Halle Berry jako Storm w filmie X-Men 2 (2003). Ponownie: postacie są rozpoznawalne wyłącznie dzięki kolorowi włosów: <https://tiny.pl/rzmbg>, dostęp: 24.05.2021.

[37] Komiksowy wizerunek Mystique: <https:// tiny.pl/rzmb7>, dostęp: 24.05.2021.

[38] Rebecca Romijn w roli Mystique: <https:// tiny.pl/rzmbr>, dostęp: 24.05.2021.

[39] Rebecca Romijn On Her X-Men Costume|Lorraine, 2015, <https://www.youtu-

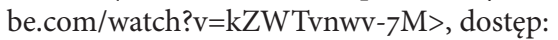
24.05.2021.

[40] It took Rebecca Romijn 9 hours to do her 'X-Men' makeup, 2018, <https://www.youtube.com/ watch?v=NCsHzYaNoYw>, dostęp: 24.05.2021. rakterystyczne wycięcie w kształcie cyfry 4[35]. Twórcy niedopuszczonego do oficjalnej dystrybucji filmu nie zdecydowali się oczywiście na tak odważny kostium.

Fantastyczna Czwórka musiała poczekać na swój filmowy debiut jeszcze kilkanaście lat. W tym czasie w kinie superbohaterskim zmieniły się trendy kostiumowe. Kostium-zbroja w naturalny sposób wyewoluował w skórzany strój. Filmy ze wspomnianej serii $X$-men oraz nieco wcześniejszej serii Blade (1998-2004) wypromowały nowy wizerunek filmowego herosa. Od teraz nie miał to być fantastyczny bohater osadzony w realistycznym świecie przedstawionym, a człowiek z krwi i kości, posiadający ponadprzeciętne umiejętności. Postulat realizmu w kinie superbohaterskim musiał być zatem realizowany również $\mathrm{w}$ aspekcie kostiumowym. Dlatego właśnie komiksowe kolorowe, lateksowe, zróżnicowane stroje członków drużyny X-Men zostały zastąpione przez czarne, skórzane, jednolite uniformy[36].

Ciekawy przypadek stanowi kostium Mystique, filmowej pomocnicy głównego antagonisty, Magneto. W komiksach niebieskoskóra zmiennokształtna Mutantka tradycyjnie ubrana jest w rodzaj białej sukni, a jej czerwone włosy powiewają swobodnie[37]. W filmach Bryana Singera postać ta, w swojej naturalnej formie, jest naga. Jej łuskowate ciało, przylegające do głowy włosy oraz niepokojące żółte oczy przywodzą na myśl węża[38]. Ciało grającej tę rolę Rebecki Romijin na początku każdego dnia zdjęciowego było w trzech czwartych pokrywane silikonem oraz ozdabiane za pomocą techniki body painting [39]. Charakteryzacja zajmowała średnio dziewięć godzin[40]. Dzięki temu swoistemu brakowi kostiumu twórcom udało się wykreować postać, która z jednej strony wygląda odpychająco, wręcz oślizgle, z drugiej zaś kusząco - wszakże jest zgrabną, nagą kobietą. Kreacja Mystique spełnia zatem postulat „idealnej nagości”. Udaje się to kosztem ogromnej inwestycji czasu, pracy i cierpliwości charakteryzatorów oraz aktorki. Nic więc dziwnego, że jest to precedens w kilkudziesięcioletniej historii komiksowych kostiumów. 
Na początku XXI wieku standardem w kinie superhero pozostają jednak skórzane kostiumy. Obok przyodzianych w nie męskich bohaterów, takich jak Daredevil czy Ghost Rider, pojawiły się kolejne superbohaterki.

Kostium filmowej Elektry jest modelowym przykładem zamiany komiksowego lateksu na skórzany strój. Zachowano przy tym charakterystyczną dla bohaterki czerwoną kolorystykę[41], a nagość nóg została zastąpiona przez odkryty brzuch[42]. Podobnej przemianie poddano kostium Catwoman, którą w filmie z 2004 roku zagrała Halle Berry. Twórcy poszli jednak o krok dalej - ich bohaterka ubrana jest w skórzany biustonosz. Ma również skórzane rękawiczki, kocią maskę, a jej nagi brzuch oplatają pasy. Wszystko to składa się na wizerunek kojarzony bardziej z dominą niż superbohaterką [43].

Wpływy z box-office'u Kobiety-Kot (2004) oraz Elektry (2005) okazały się wyjątkowo niezadowalające[44]. I choć ciężko jednoznacznie zawyrokować, jak duży wpływ na wysokość przychodów z obu filmów miała płeć głównych bohaterek, faktem jest, iż na kolejny film z kobietą w roli głównej fanom komiksów DC przyszło czekać do roku 2017, zaś fanom Marvela - do 2019.

Przed powstaniem Marvel Cinematic Universe[45] na ekranach kin zdążyła zagościć jeszcze jedna bohaterka Marvel Comics. W 2005 roku miała bowiem miejsce premiera filmu o Fantastycznej Czwórce. Również tym razem twórcy zdecydowali się na kostiumy silnie wzorowane na komiksowych strojach, wykonane jednak $\mathrm{z}$ grubszego materiału[46]. Warto zauważyć, że na zdjęciach promocyjnych oraz plakatach bohaterka grana przez Jessikę Albę pojawia się w rozpiętym kombinezonie, podczas gdy w filmie jej strój jest zapięty pod szyję[47]. Wybranie do roli Sue Storm popularnej wówczas głównie ze względu na swą urodę aktorki oraz wspomniany zabieg promocyjny jasno świadczą o tym, jaką rolę w filmie przypisano postaci Niewidzialnej Kobiety.

$\mathrm{Z}$ powyższych rozważań na temat rozwoju kostiumów filmowych superbohaterek na przestrzeni lat płyną dwa kluczowe wnioski. Po pierwsze, stroje żeńskie przeszły ewolucję tożsamą z ewolucją strojów męskich. W początkach gatunku filmowcy starali się odwzorować komiksowe kostiumy jak najwierniej, co nie zawsze okazywało się możliwe. Barierą były nie tylko ograniczenia wynikające ze zmiany medium, ale również możliwości techniczne. Wraz $\mathrm{z}$ upływem czasu i rozwojem gatunku filmowe kostiumy superbohaterskie stawały się coraz bardziej pragmatyczne - twórcom zaczęło zależeć bardziej na realizmie niż na kopiowaniu prze-

[41] Zanim Elektra otrzymała własny film, zadebiutowała w produkcji Daredevil (2003), w której jej kostium był czarny - miał zatem niewiele wspólnego z wizerunkiem znanym czytelnikom komiksów.

[42] Kostium filmowej Elektry, w którą wcieliła się Jennifer Garner: <https://tiny.pl/9mjg2>, dostęp: 24.05.2021. Komiksowy wizerunek postaci: <https://tiny.pl/rzmvn>, dostęp: 24.05.2021.

[43] Przesadnie rozneglizowana Halle Berry w kostiumie Catwoman: <https://tiny.pl/rzmbw $>$, dostęp: 24.05.2021.

[44] J. Ruimy, 10 Worst Superhero Box Office Bombs, 2015, <https://screenrant.com/worst-superhero-movie-box-office-bombs/>, dostęp: 24.05.2021.

[45] Marvel Cinamatic Universe, czyli Kinowe Uniwersum Marvela, to seria filmów, której bohaterami są postacie powołane do życia na łamach komiksów wydawnictwa Marvel Comics. Do czasu, w którym pisany jest niniejszy tekst, premierę kinową miały dwadzieścia trzy filmy z serii, które zbiorczo zostały nazwane przez twórców Infinity Saga [Saga nieskończoności]. MCU charakteryzuje fakt, iż akcja wszystkich filmów rozgrywa się $\mathrm{w}$ tym samym świecie przedstawionym, mimo iż każdy z nich stanowi autonomiczne dzieło filmowe. Jest to rozwiązanie dziś powszechne w świecie komiksowych adaptacji, będące jednak nowatorskie w początkach istnienia uniwersum, czyli we wczesnych latach dwutysięcznych.

[46] Jessica Alba w roli Sue Storm: <https://tiny. pl/9mjg8>, dostęp: 24.05.2021.

[47] Fantastyczną Czwórkę (2005) promowano plakatami, na których widoczny był dekolt bohaterki. Przy okazji sequela nie powtórzono tego zabiegu: <https://tiny.pl/rzmbs>, dostęp: 24.05.2021. 
rysowanych rozwiązań komiksowych. Niemal każdy z przywołanych kostiumów, niezależnie od czasu powstania, pozostaje jednak odtwórczą wersją komiksowego pierwowzoru. Pojedyncze przykłady kreatywnych rozwiązań nie zapisały się na stałe w kulturze popularnej (pierwszy kostium ekranowej Wonder Woman) lub cieszą się złą sławą (strój Halle Berry w filmie Kobieta-Kot).

Drugi wniosek dotyczy obecności superkobiet $\mathrm{w}$ kinie. Dostrzegalny jest bowiem fakt, iż w czasach poprzedzających powstanie MCU obecność ta była wręcz marginalna. Mimo debiutu komiksowych adaptacji w roku 1941 pierwsza superbohaterka pojawiła się na ekranie dopiero $\mathrm{w}$ połowie lat sześćdziesiątych. Najwięcej kobiecych bohaterek wniosło do gatunku uniwersum Batmana, zaś Marvel Comics dopiero w 2000 roku zaczęło podejmować pierwsze próby wypromowania w kinie swoich superbohaterek. Poza bohaterkami serii filmów o drużynie X-men żadna z superkobiet nie spotkała się jednak z ciepłym przyjęciem widowni (powodem była najpewniej kiepska jakość tych filmów), co na długie lata pogrzebało wszelkie plany nakręcenia filmu z superbohaterką w roli głównej.
B I B L I O G R A F I A

Burton B., "Batman Returns" at 25: Stars reveal script cuts, freezing sets and aggressive penguins, 2017, $<$ https://www.hollywoodreporter.com/heat-vision/ batman-returns-at-25-stars-reveal-script-cuts-freezing-sets-aggressive-penguins-1013942, dostęp: 21.04.2020

Daniels L., Batman: The Complete History: The life and times of the Dark Knight, San Francisco 2004

It took Rebecca Romijn 9 hours to do her 'X-Men' makeup, 2018, <https://www.youtube.com/watch?v= NCsHzYaN0Yw, dostęp: 21.04.2020

Jeffries D.H., From the top of the cowl to the tip of the cape. The cinematic superhero costume as impossible garment, "Cinephile: The University of British Columbia’s Film Journal” 2013, vol. 9, nr 2, s. 30-37.

McCloud S., Zrozumieć komiks, Warszawa 2015

Rebecca Romijn On Her X-Men Costume|Lorraine, 2015, $<$ https://www.youtube.com/watch?v=kZWTvnwv-7M, dostęp: 21.04.2020

Ruimy J., 10 Worst Superhero Box Office Bombs, 2015, $<$ https://screenrant.com/worst-superhero-movie-box-office-bombs/, dostęp: 21.04.2020

<https://www.boxofficemojo.com/release/rl405081 4465/weekend/, dostęp: 21.04.2020 